\title{
Research on the Market Demand of Solid Wood Furniture Based on Internet Survey
}

\author{
Shiyan Wu \\ College of Arts and Design \\ Beijing Forestry University \\ Beijing, 100083, P. R. China
}

\author{
Yi Feng* \\ College of Arts and Design \\ Beijing Forestry University \\ Beijing, 100083, P. R. China \\ fengyid@163.com \\ *Corresponding author
}

\begin{abstract}
From the perspective of consumers' behavioral characteristics and their consumption habits, this paper conducts surveys from multiple dimensions to carry out market research on consumers' cognition and purchase intention of solid wood furniture. Through the analysis and processing of the survey results, it is found that consumers prefer pure and fresh Nordic style in terms of the style of solid wood furniture and prefer plain wood color in terms of color. They have higher requirements on the function, comfort, and beauty of solid wood furniture. Through the analysis of the survey results, the paper puts forward some suggestions for the development of solid wood furniture for enterprises and manufacturers.
\end{abstract}

Keywords-market survey, solid wood furniture, consumption cognition, consumption intention

\section{INTRODUCTION}

In recent years, with the rapid development of China's economy and the enhancement of the awareness of sustainable development, along with increasing improvement of people's living standards, solid wood furniture is more and more favored by consumers. Over the past few years, China's furniture industry has been growing steadily on the whole. The competition among furniture enterprises is increasingly fierce. If furniture enterprises want to take a place in the fierce market competition, they should not only perfect and improve product quality, but also pay attention to consumers' cognition and fully grasp their actual needs, psychological characteristics and behavioral characteristics.

In recent years, consumers' demand for natural and environmental-friendly solid wood furniture returns again. It becomes a market new favor. Solid wood furniture always makes us connect with the Chinese style without light and novel feeling. However, over the past two years, while continuing its classic style, many brands of solid wood furniture with Chinese characteristic add new kinds of wood by joining a lot of fashionable elements.

Wood is the gift of nature. The relationship between wood and human always goes hand in hand and benefits us constantly. Since ancient times, human life has been inseparable from wood, and the history of Chinese architecture and furniture is almost a history of wood culture. Our affection with wood extends from the material to every aspect of our

This study was financially supported by the Fundamental Research Funds for the Central Universities (2018RW13) and the Fundamental Research Funds for the Central Universities (2015ZCQ-YS-01). spiritual life. In addition to technological development and policy promotion, the key to the development of solid wood furniture industry is to meet consumer demand [3]. At present, we should grasp the characteristics and purchase intention of solid wood furniture consumers in China, which has a certain guiding significance for the development of solid wood furniture industry and product sales.

\section{PREPARATION FOR THE RESEARCH AND THE DESIGN OF THE QUESTIONNAIRE}

\section{A. The purpose of research and survey}

In recent years, the solid wood furniture market has shown a trend of revival. Due to the increasing improvement of people's living standards and our increasing demand for a better life, the consumption demand of consumers and the various requirements on products have also been greatly improved. It is of great significance for the development and research of the market of solid wood furniture and the promotion of brands to find out consumers' market demand for solid wood furniture through investigation.

\section{B. The contents and method of research}

An online questionnaire is used to obtain the required information and advice in this research. The research analyzes its service life, style, decorative techniques, advantages and disadvantages, color and the way to understand solid wood furniture. 87 online questionnaires are issued and 87 questionnaires are collected.

\section{Design of the questionnaire}

The research object of this paper is "the consumers of solid wood furniture". Their purchase intention, the cognition of the product and the influencing factors of the purchase are investigated. The questionnaire is designed with a clear and reasonable structure so that the respondents can quickly understand the contents of the questionnaire. The questionnaire structure is as follows:

\section{1) The title of the questionnaire}

The title of the questionnaire should highly summarize the topic of this survey. Therefore, the title of this questionnaire is 
"the questionnaire on cognition and satisfaction of solid wood furniture".

2) The information of respondents

This section is the basic information of the respondents, including their gender, age, occupation, education background, income and region.

3) The main body of the questionnaire: the main body of this questionnaire includes the following aspects:

a) A survey on consumers' cognition on solid wood furniture in the market.

b) A survey on the daily user experience of people who currently own solid wood furniture and the purchase intention of potential solid wood furniture buyers.

c) A survey on the influencing factors in buying solid wood furniture.

Several key questions about the design and use of existing solid wood furniture are investigated by choice questions, which are divided into single choice and multiple choices.

\section{ThE STATISTICS AND ANALYSIS OF THE RESUlts OF THE SURVEY}

\section{A. The collection of sample data and data explanation}

In this survey, 87 questionnaires are sent online and 87 valid questionnaires are collected. Since the questionnaire is distributed online, it is more objective and it can get rid of the geographical limitation and crowd concentration.

In this survey, the proportion of men accounts for $40.23 \%$ and women $59.8 \%$. In choosing products, consumers' age is an important factor affecting their choice. Younger people are more concerned about the appearance and reputation of products, while older people have higher requirements on the reliability and comfort of products. In this survey, the age of most people is between 21 and 30 years old, accounting for $77.01 \%$ of the total population. $12.33 \%$ is aged under 20 years old, 5.75\% between 41 and 50, 4.6\% aged between 31 and 40, and $1.15 \%$ aged over 51 , as shown in Fig. 1.

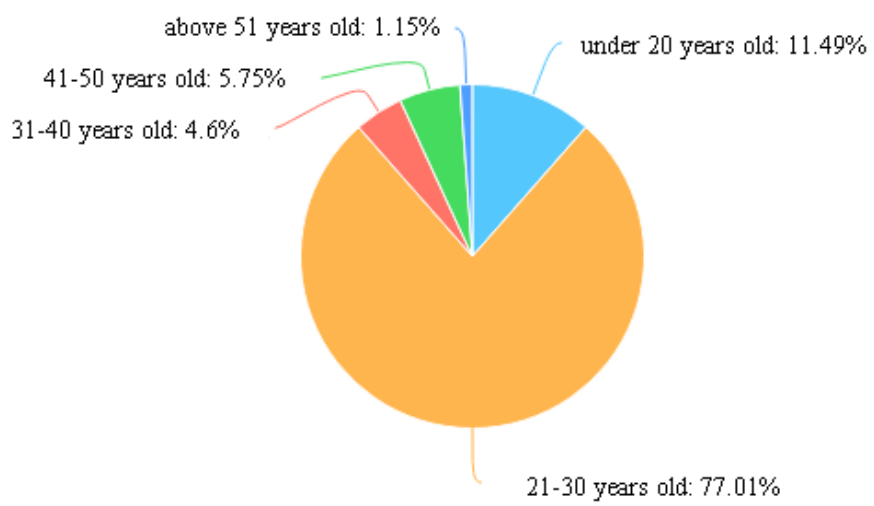

Fig. 1. The proportion of age of respondents

\section{B. Analysis on the factor of income}

Among all respondents, those with incomes below 2,000 Yuan accounts for 39.08\%, incomes between 2001 and 4,000 Yuan for 22.99\%, incomes between 4,001 and 6,000 Yuan for 18.39\%, incomes between 6,001 and 8,000 Yuan for 6.9\%, incomes between 8,000 and 10,000 Yuan only for 4.6\%, and incomes above 10,001 Yuan for $8.05 \%$. The salary of respondents is shown in Fig. 2.

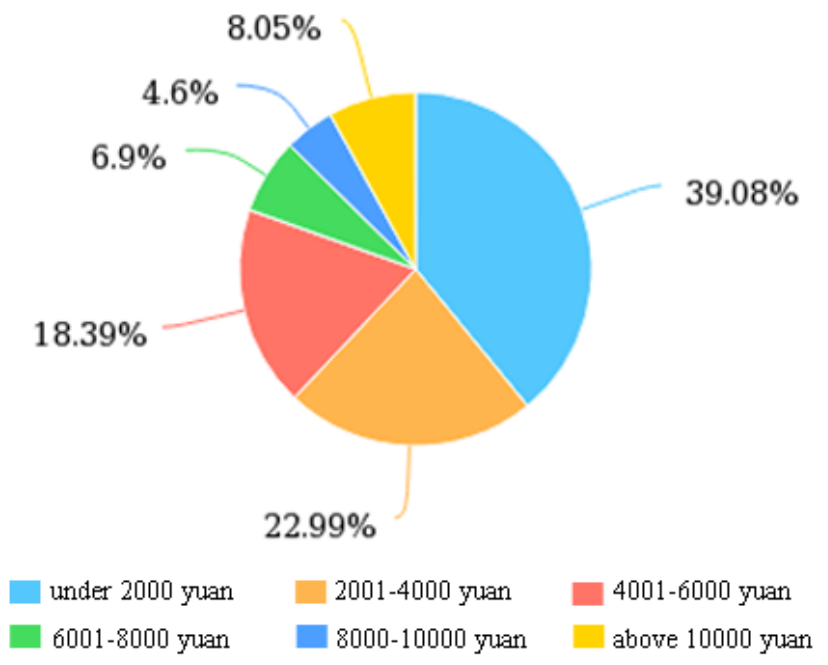

Fig. 2. The proportion of salary of respondents

\section{Analysis of the factor of occupation}

Different occupations will affect how and how often products are used. In this survey, students are the largest population, accounting for $56.32 \%$. Professional and technical personnel (such as teachers, lawyers, doctors, nurses, engineers, architects, accountants, etc.) ranks second, accounting for $14.94 \%$. Freelancers rank the third, accounting for $8.05 \%$, followed by company employees, $6.9 \%$, housewives, $4.6 \%$ and government employees, $2.3 \%$. The smallest groups are business managers (including private owners) and retirees, both accounting for $1.15 \%$ of the total. People with other occupations account for $4.6 \%$. The occupation of respondents is shown in Fig. 3.

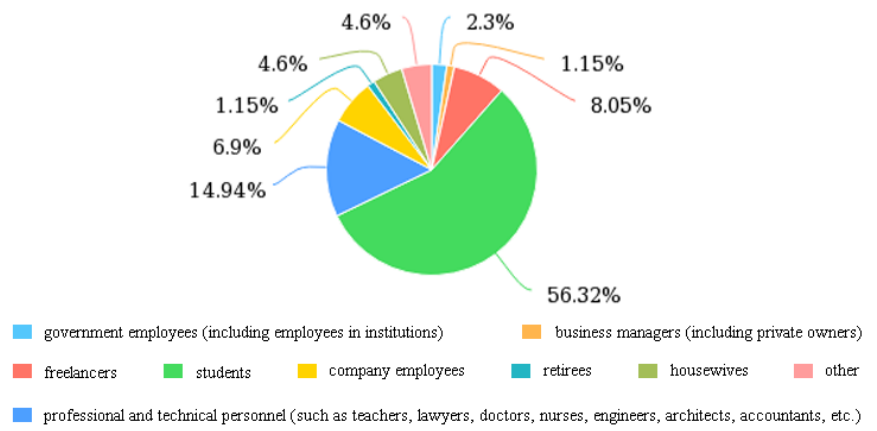

Fig. 3. The proportion of occupation of respondents 


\section{Analysis of the factor of educational background}

The survey results show that education, as an important means to improve the quality of citizens in modern society, plays a decisive role in improving the quality of consumers. Education background will indirectly affect consumers' consumption level, structure and concept. Consumption pattern not only has an important impact on consumers and families but also on the whole social and economic development. Among the respondents, those with master's degree account for the largest proportion, reaching $44.83 \%$, followed by those with bachelor's degree, accounting for $37.93 \%$. The proportion of senior high school students or below is $13.79 \%$, and the proportion of junior college students is $2.3 \%$. Those with doctoral degrees are the smallest group with only $1.15 \%$. The education background of respondents is shown in Fig. 4.

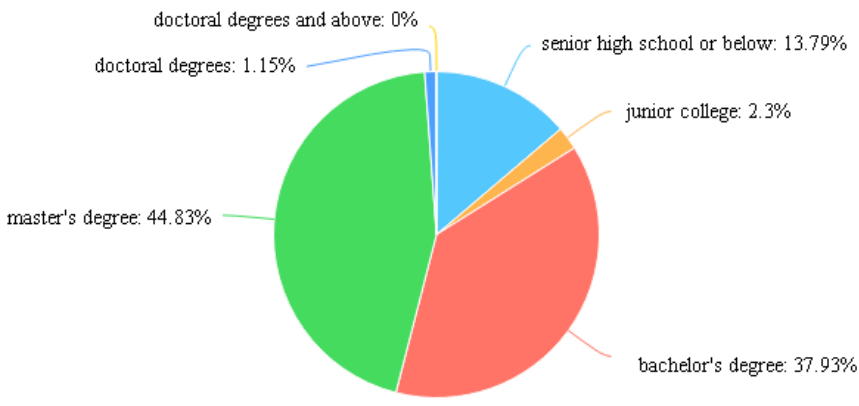

Fig. 4. The proportion of educational background of respondents

\section{E. Analysis of the factor of geographical distribution}

In the geographical survey of consumers, consumers in Beijing account for 51.14\%, Liaoning $27.27 \%$ and foreign groups 5.68\%. Consumers in Hebei, Inner Mongolia, Guangdong and Shanghai account for $2.27 \%$ and those in Hongkong, Yunnan, Guangxi, Shanxi, Henan and Heilongjiang account for $1.14 \%$ as shown in Fig. 5.

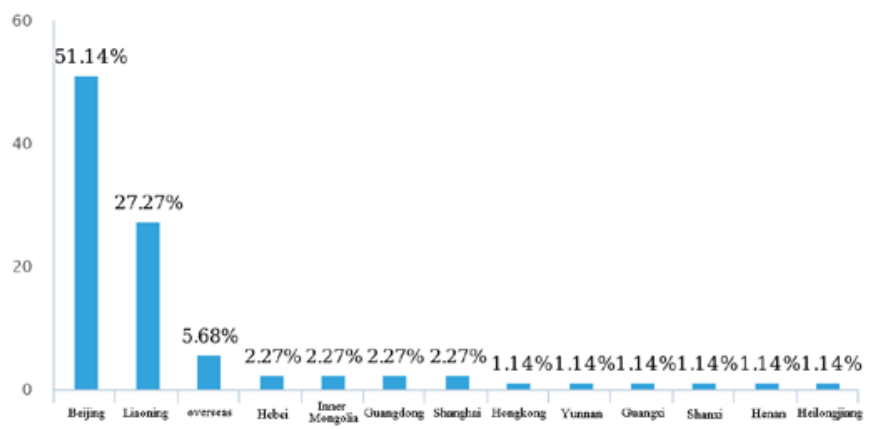

Fig. 5. Proportion of geographical distribution of respondents

\section{F. Analysis on consumers' cognition on solid wood furniture.}

According to the survey, the majority of people have little understanding on solid wood furniture, accounting for $44.83 \%$. Those without understanding on solid wood furniture account for $28.74 \%$. Those who have basic knowledge on it account for $25.29 \%$. And those who know it very well only account for $1.15 \%$. From this point of view, people are not very familiar with solid wood furniture. It still needs publicity and guidance from society and the market to promote the market of solid wood furniture. See Fig. 6.

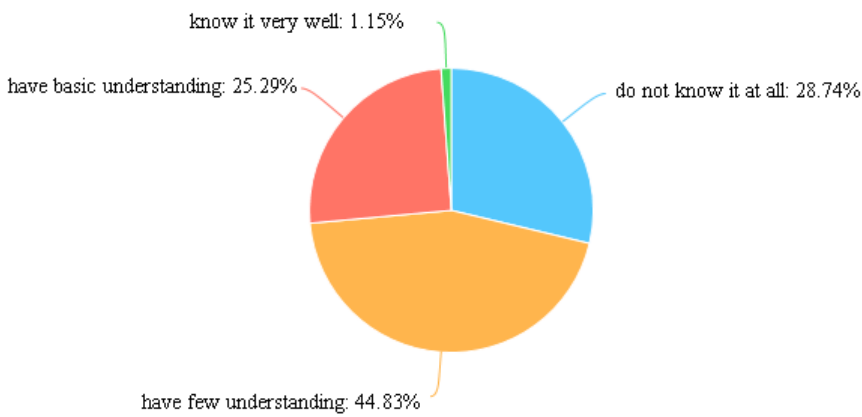

Fig. 6. The proportion of understanding of solid wood furniture for respondents

Most consumers get to know solid wood furniture through offline stores, accounting for $64.37 \%$, which indicates that people still pay attention to physical experience when choosing solid wood furniture. Online stores such as Taobao and JD account for $48 \%$. Online shopping has entered public life. The products people buy online have extended from small products to large-sized products such as furniture. Furthermore, consumers get to know solid wood furniture through exhibition and museum, thus increasing their cognition on solid wood furniture. Additionally, they also know solid wood furniture through social media such as Wechat account and Weibo, which account for $32.18 \%$. $22.99 \%$ of them get to know it through books and newspaper. $6.9 \%$ of them know solid wood furniture through other channels. See Fig. 7.

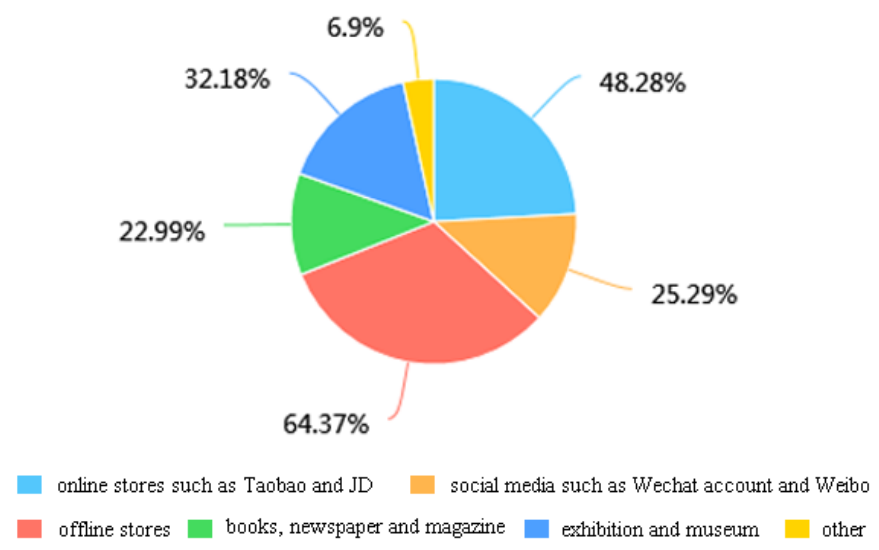

Fig. 7. Proportions of channels for respondents to know solid wood furniture

Most people expect to use furniture for 5-10 years, accounting for $35.63 \%$, followed by $19.54 \%$ who expect to use furniture for more than 30 years, and $18.39 \%$ who expect to use furniture for $10-15$ years. $13.79 \%$ of them expect to use furniture for 15 -20 years, $8.05 \%$ for less than 5 years, and only $4.6 \%$ for $20-30$ years. See Fig. 8. 


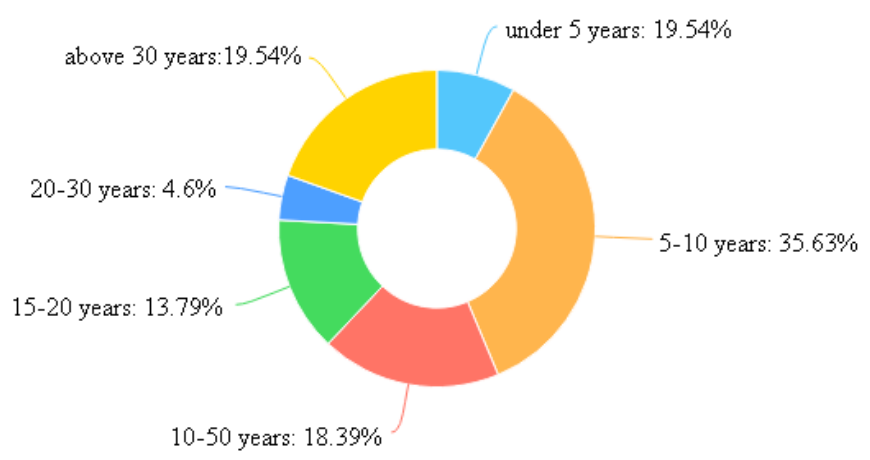

Fig. 8. The proportion of service life of the furniture

In the survey, $74.71 \%$ consumers value the appearance beauty when choosing solid wood furniture, followed by practical consideration, accounting for $67.82 \%$, $59.77 \%$ for comfort, $47.13 \%$ for easy to take care, $42.53 \%$ for long service life, $39.08 \%$ for the function of solid wood furniture, $2.3 \%$ for other aspects. See Fig. 9.



Fig. 9. The proportion of respondents' emphasis on solid wood furniture

For the style of solid wood furniture, most consumers choose the rustic Nordic style, accounting for $60.44 \%$, followed by new Chinese style with $49.45 \%, 30.77 \%$ for new classical style, $23.08 \%$ for traditional Chinese style and classical European style, and 3.3\%for other styles. See Fig. 10.

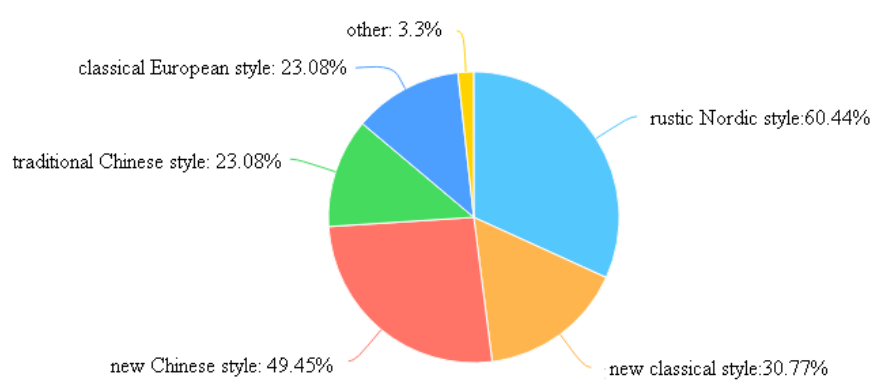

Fig. 10. The proportion of the style of solid wood furniture favored by respondents
For the decoration of solid wood furniture, most consumer favor carving, accounting for more than half, for $52.87 \%$. And $36.78 \%$ consumers choose to not decorate it. $31.03 \%$ of them choose to mix it with other materials. And $29.89 \%$ choose Mosaic technique. $17.24 \%$ of them like to paint them in color. 5.75\% choose other decorative techniques. See Fig. 11.

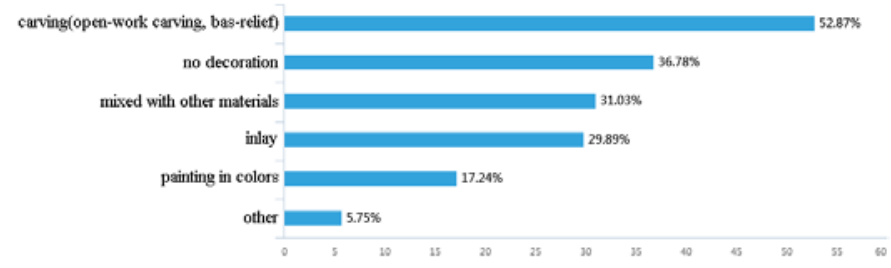

Fig. 11. Proportions of choices for decorative techniques of solid wood furniture by respondents

As many as $70.11 \%$ consumers like the plain wood color. $44.83 \%$ for light wood color, $41.38 \%$ for white, $33.33 \%$ for dark wood color, $18.39 \%$ and $16.09 \%$ for black brown and dark red respectively and $5.75 \%$ and $4.6 \%$ dark purple and other colors respectively. See Fig. 12.

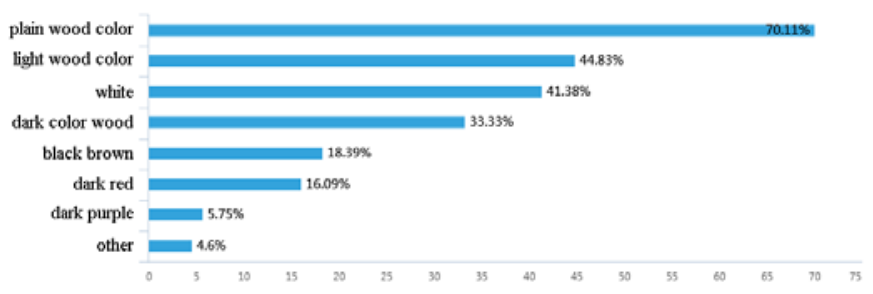

Fig. 12. The proportion of color for solid wood furniture favored by respondents

For the materials of solid wood furniture, only $10.34 \%$ choose plastic, and most consumers prefer metal and other wood, accounting for $37.93 \%$, followed by stone and leather accounting for $36.78 \%$, soft package and glass accounting for $35.63 \%$ and $28.74 \%$ respectively. See Fig. 13.

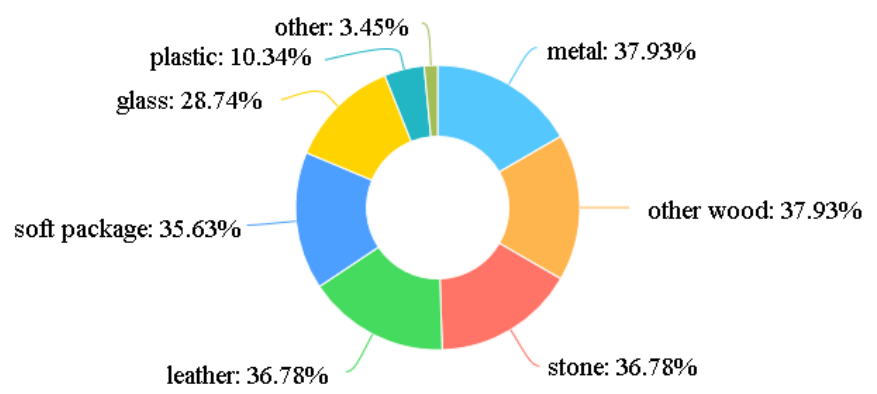

Fig. 13. The proportion of choices for mixed materials of solid wood furniture by respondents

\section{CONCLUSION}

With the continuous improvement of people's living standards, people's taste of furniture products is also constantly improved. Solid wood furniture is more and more favored by consumers because of its environmental-friendly and beauty. In 
recent years, in the whole industry of solid wood furniture, new Chinese style and simplicity with European style are more and more popular among consumers. And their demand for the style of solid wood furniture gets higher and higher.

To sum up, through the analysis of the survey on consumer psychology and design elements, it requires to take a comprehensive consideration on consumers' behavioral characteristics, solve the problems in existing products and engage in planning work in the early stage of design in accordance with functional innovation, style appeal, colors, the material of furniture, decorative technique and other aspects in the process of the practice of the design of solid wood furniture.

The following suggestions are proposed based on the research results. (1) It should increase the years of use of furniture in the design of solid wood furniture so as to design furniture products suitable for the needs of different groups. (2) The design style has changed to the new Chinese style and European fresh style. Therefore, it is necessary for designers to get rid of the old and bring forth the new, explore consumers' potential consumption psychology and create the newest and advanced design style. (3) It should give full play to the advantage of solid wood furniture in the design to attract more consumers. Only under the joint effort of people, market and products can the design be more favored by consumers. Only by taking the feasibility of each respect into full consideration can we design the solid wood furniture that accords with consumers' physiological and psychological demand.

\section{ACKNOWLEDGMENTS}

This study was financially supported by the Fundamental Research Funds for the Central Universities (2018RW13) and the Fundamental Research Funds for the Central Universities (2015ZCQ-YS-01).

\section{REFERENCES}

[1] Zhou Chengmin, Zhu Zhifan, Yu Mengnan, Fu Xiaoman, Jake Kaner, Research on the Design of Solid Wood Furniture Based on Psychology of Young Consumers[J]. Packaging Engineering, 2018, 39(24):226-231.

[2] Li Mingxiu, Li Kezhong, On the History and Artistic Characteristics of Chinese Furniture and Decoration[J]. Packaging Engineering, 2010, 31(06):110-113.

[3] Wang Chenxiao, Research on the Influence of Consumers' Cognition on the Intention of Solid Wood Furniture[D]. Northeast Forestry University, 2016

[4] Hou Haiou, Research on the Interior Design of Chinese Residence Based on Consumers Psychology[D].Hunan University of Technology, 2012

[5] Zhang Hanning, Research on the Color Image of Modern Furniture[D]. Nanjing Forestry University, 2012

[6] Zhi Wenling, On Choice of the Color of Furniture [J]. China Science and Technology Information, 2005(11):175.

[7] Xiao Wu, Research on the Use of Morphological Semantics in the Design of Furniture[D]. Central South University of Forestry and Technology, 2010

[8] Li Shan, Xu Kaimeng, Chen Guoying, Duan Dong, Research on Appearance Design of Modern Solid Wood Furniture[J]. China Forest Products Industry, 2016, 43(07):32-35. 